\title{
Teorias Sociológicas Comparadas e Aplicadas Bourdieu, Foucault, Habermas e Luhmann face ao Direito ${ }^{1}$
}

Pierre Guibentif ${ }^{2}$

\begin{abstract}
$\mathrm{R}$ incidindo sobretudo em quatro autores: Pierre Bourdieu, Michel Foucault, Jürgen Habermas e Niklas Luhmann.

É composto de três partes: algumas breves reflexões sobre o que está em jogo no trabalho sobre teorias sociológicas comparadas e aplicadas; uma proposta de duas modalidades de comparação entre os autores escolhidos; e a formulação de algumas orientações, derivadas da comparação realizada, para o trabalho de observação empírica.
\end{abstract}

Palavras-chave: Teorias sociológicas; Sociologia do direito; Quadro teórico; Agir; Instâncias.

\section{Introdução}

\section{Da possibilidade e necessidade de aplicar teorias no trabalho empírico}

tema das relações entre teoria e empiria já tem uma longa tradição. Mas a situação actual tem as suas especificidades. As teorias hoje disponíveis - e nisto diferem das reflexões teóricas de muitos autores que dominaram a disciplina em épocas anteriores - foram elaboradas tendo em atenção um abundante trabalho de terreno. Nestas circunstâncias, é elevada a probabilidade de tais teorias poderem ser úteis na abordagem de objectos empíricos. Logo, já não se trata, apenas, de organizar melhor os conhecimentos recolhidos no trabalho empírico ao consolidar teorias de médio alcance (Merton, 1948, p. 166; 1968); trata-se também de articular e melhor desenvolver teorias de grande alcance, agora disponíveis, procurando maneiras de as remobilizar efectivamente no trabalho empírico.

É precisamente esta a principal finalidade do instrumento que apresentarei neste ensaio, a que chamarei, de maneira um tanto banal, um "quadro teórico", dando, no entanto, um sentido técnico específico a esta expressão. Face ao desafio de relacionar teorias e investigação empírica, este quadro teórico constitui uma ferramenta para facilitar a passagem ordenada de ideias e, mais importante, de interrogações, entre estes dois planos. Queria aqui insistir precisamente nesta finalidade de passagem ordenada de ideias e interrogações. Não se pretende mais do que isto: não se propõe uma meta-teoria, que se poderia levar aos factos para os explicar completamente; trata-se de levar aos factos, a partir das teorias, interrogações melhor formuladas e focalizadas. E também não se pretende que a abordagem à empiria resolva as controvérsias teóricas. Estas poderão até ser agudizadas. Trata-se antes de alimentar o questionamento das teorias e, desta maneira, de cultivar a sua diversidade.

\section{Âmbito do conceito de "Teorias"}

Entendo aqui por teorias os pensamentos de autores, abordados na sua globalidade, na sua individualidade e, sempre que possível, na sua força própria. Quero associar a este esclarecimento terminológico uma chamada de atenção em



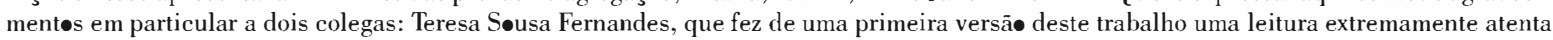
e cujas observaçōes foram cruciais para as reflexōes aqui apresentadas, e António Teixeira Fernandes, pela sua muito pertinente e estimulante arguição.

2 Prøfessor associad• do ISCTE. Contact•: pierre.guibentif@iscte.pt.
} 
particular: os textos teóricos não podem ser lidos isoladamente, devem ser lidos no contexto mais abrangente das obras em que se inserem, isto é, no conjunto dos trabalhos publicados por um autor ao longo de vários anos, percorrendo vários temas e elementos de reflexão, desenvolvendo sobretudo a sua lógica global de reflexão e, muitas vezes, alterando esta lógica.

Existem várias, e poderosas razões, que conduzem a insistir num tal modo de leitura. Mas este modo de leitura é particularmente importante na perspectiva do trabalho de aplicação de teorias na investigação empírica. Recordo: o desafio é articular procedimentos de observação de uma realidade concreta e as reflexões teóricas de um determinado autor. Isto far-se-á melhor e mais facilmente e se se tiver uma noção da articulação que este autor, ele próprio, estabeleceu entre as suas reflexões teóricas e os seus trabalhos de observação. E por trabalho de observação entende-se, aqui, tanto as operações de trabalho sociológico empírico, como as experiências vividas do contexto histórico, experiências essas que, de alguma maneira, motivaram o trabalho teórico e que neste foram reenquadradas. Ora, esta articulação raramente se compreende a partir de leitura de textos isolados e apenas poderá ser reconstituída a partir de uma visão de conjunto sobre o percurso e a bibliografia do autor.

\section{Potencialidades dos procedimentos comparativos em matéria de teorias}

Uma das razões da insistência no trabalho comparativo é que comparar vários autores oferece garantias de algum distanciamento, alguma independência em relação aos autores estudados. Quando teorias constituem ofertas intelectuais fortes, e são estas que merecem ser contempladas com toda a atenção, é particularmente importante cuidar dos mecanismos que nos poderão preservar de cair, por assim dizer, sob a tutela intelectual dos seus autores. A comparação é um destes mecanismos.

Uma segunda razão é que a comparação facilita grandemente a leitura de cada um dos autores contemplados. Recordo algumas das virtualidades do trabalho comparativo sob este ponto de vista. Tem uma utilidade mais óbvia quando os autores se referem uns aos outros, debatem uns com os outros, e que os seus conceitos, em virtude destes debates, se definem, não apenas por referência ao quadro conceptual de um autor, mas por referência aos conceitos de outros autores. Uma utilidade tão importante ou até mais se, como referi há pouco, no estudo dos autores, se aprofundar a identificação das maneiras de relacionarem trabalho teórico e trabalho de observação. Estes modos de relacionamento com a realidade social não são fáceis de se caracterizar quando se considera um autor isoladamente mas revelam-se ao leitor com toda a sua nitidez a partir do momento em que nos colocamos em condição de observar diferenças entre autores. Para terminar esta introdução, queria recordar o meu principal objectivo: tirar partido o mais plenamente possível das propostas teóricas disponíveis, com toda a sua força, isto é, a sua coerência. Recuso, assim, duas formas de comparação, entre as quais procuro um meio termo: por um lado, a simples "bricolage" - alinhamento, em moldes de catálogo, de conceitos de autores diversos; por outro lado, a ambição desmedida de construir uma teoria que fizesse a síntese das propostas existentes ambição desmedida e, mais importante ainda, indutora de graves efeitos de enfraquecimentos dos conceitos e modelos.

\section{Duas modalidades de comparação}

\section{Um tema comum:}

\section{o desencanto da razão jurídica}

Proporei, primeiro, uma comparação que se apoia nos próprios autores, sem recorrer a referências externas. Neste primeiro passo, tentarei identificar um tema comum, que permita caracterizá-los melhor, um em relação aos outros. A identificação de um tal tema, aqui e agora, fornece-me, aliás, a possibilidade de recordar brevemente alguns traços mais salientes das teorias destes autores. E de recordar desta maneira porque é que se tornaram, nestas últimas décadas, referências centrais na literatura de sociologia do direito.

Um tema comum aos quatro autores é, de facto, o desencanto da razão jurídica ${ }^{3}$. Se nos

${ }^{3}$ O uso da palavra "desencanto" na formulação deste tema transversal foi-me sugerido por Nuno Coelho na discussão de uma aula dedicada a este tema, no mestrado "Novas Fronteiras do Direito". Não quero deixar de agradecer aqui esta feliz intuição semântica. 
quiséssemos inserir mais cuidadosamente na tradição sociológica, deveríamos dizer: o segundo desencanto. O primeiro, como se sabe, é o que Max Weber verificou (Weber, 1921, p. 308). Este autor, analisando as ordens jurídicas nascidas com a modernidade, destacou, como traço característico destas, a distância que se tinha estabelecido entre o mundo da tradição e das referências religiosas, a magia - Zauber -, por um lado, e, por outro lado, o novo saber jurídico, assente no direito positivo e na profissionalização dos conhecedores desta matéria - Entzauberung. Quase um século mais tarde, é de outro desencanto que se trata.

É necessário recordar que, com o Iluminismo, se tinha assistido ao que também poderíamos chamar um "encantamento do direito", embora um encantamento de natureza radicalmente diferente do que resultava das afinidades entre o direito e um mundo de magia. $\mathrm{O}$ direito acabava de se autonomizar em relação a referências transcendentes; mas, aos olhos de muitos pensadores, surgiu um outro motivo de "entusiasmo": o direito, com as suas novas características, poderia ser o instrumento pelo qual os homens iriam fazer a sua história. Esta ideia entusiasmou não apenas filósofos, mas também juristas e os que chamaríamos hoje em dia de políticos do direito. E esta ideia está na base dos dois grandes processos que fazem a história do direito moderno: o Constitucionalismo e o processo das Codificações. O Constitucionalismo, assente no reconhecimento dos direitos dos cidadãos em participar na história da Nação (Habermas, 1963; Fernandes, 2000; Hespanha, 2004), e o processo de Codificação do direito privado e do direito penal, baseado no reconhecimento das pessoas enquanto sujeitos de direito, isto é, sujeitos da sua actividade, em particular da sua actividade económica (Gilissen, 1979/1988).

Se os quatro autores que vou comparar agora têm algo em comum, então é a sua maneira de pôr em causa esta representação do direito como instrumento pelo qual os sujeitos fazem a sua história.

\section{Niklas Luhmann}

Este autor assume a posição mais radical (ver fragmento 1): radical porque afirma liminarmente que, simplesmente, não há sujeitos. A sociedade, nas suas palavras, "não é constituída por seres humanos" (Luhmann, 1984/1995, pp. 346-255); estes seriam apenas um elemento do seu contexto. $\mathrm{Na}$ sociedade, no entanto, existe direito. Há uma actividade jurídica, que Luhmann aborda, aliás, sob a perspectiva da comunicação jurídica. Mas este direito, esta actividade jurídica, sustenta-se a si própria. As operações jurídicas não devem nada, enquanto operações jurídicas, a qualquer sujeito que invista nelas as suas aspirações à justiça, ou os seus projectos políticos. As operações jurídicas encontram toda a sua substância, a sua necessidade e as suas condições de possibilidade nas operações jurídicas anteriores (Luhmann, 1993/2004). Para Luhmann, toda a realidade social reside neste fenómeno improvável - para utilizar uma palavra que ele próprio gosta de utilizar - da possibilidade e necessidade de encadeamento de operações de uma determinada natureza, encadeamento que faz existir sistemas sociais, que faz a realidade social.

\section{Fragmento 1: Niklas Luhmann}

"O nosso ponto de partida é que os sistemas sociais não são constituídos por sistemas psíquicos, menos ainda por seres humanos em carne e osso." (Soziale Systeme, 1984, p. 346) "Apenas atingimos um fundo sólido, se nos lembrarmos que os sistemas sociais são constituídos por comunicações (...) Para poder dizer que se está perante uma operação jurídica, deve portanto haver uma comunicação (...) Mas não basta obviamente qualquer comunicação (...) Apenas pertence ao sistema jurídico uma comunicação orientada por um código, ou uma comunicação que afirma uma atribuição dos valores 'de acordo com o direito' ['Recht'] e 'contrário ao direito' ['Unrecht']; com efeito, apenas uma tal comunicação procura e afirma uma conexão recorrente no sistema jurídico (...)" (Das Recht der Gesellschaft, 1993, p. 67) "Pois apenas os sistemas podem servir de meio para as Luzes, não um público a discutir livremente (...) / (...) A positivização do direito é desta maneira um componente essencial do processo civilizacional das Luzes, isto é uma conversão de princípio do direito para um grau mais elevado de complexidade, para uma apreensão mais abrangente e uma redução mais eficaz da complexidade." (Soziologische Aufklärung 1967, pp. 77/81). 
No entanto, neste modelo sem sujeitos, não deixa de existir alguma forma de "razão": as operações jurídicas, ao repetirem-se e encadearem-se, reproduzem distinções - nomeadamente entre o que é válido e o que não é válido. E estas distinções - e a forma como se distinguem de outras distinções, nomeadamente entre o bem e o mal, entre o que é meu e o que é teu, entre o que é verdadeiro e o que é falso -, constituem na modernidade uma importante ferramenta de construção simbólica do nosso universo ${ }^{4}$. Tal ferramenta, na medida em que permite construir o universo, aproxima-se da noção de razão. $O$ direito pode ser "um meio para a Aufklärung" (Luhmann, 1967, p. 77). Mas esta Aufklärung não resulta de uma vontade individual de conhecimento, mas sim de uma actividade societal, a continuada operação dos vários sistemas sociais. Daí que Luhmann fale de Iluminismo sociológico ${ }^{5}$.

\section{Pierre Bourdieu}

Gosto de aproximar a teoria de Niklas Luhmann da teoria de Pierre Bourdieu (ver fragmento 2), porque é notável a convergência em pontos essenciais, entre estes dois sociólogos que, em termos políticos, se encontram bastante afastados um do outro. Como Luhmann, Bourdieu admite que o mundo social produz, enquanto mundo social, categorias que têm relevância para a prática, sem que essas resultem do esforço intelectual de sujeitos individuais. Admite uma "razão" associada à prática do direito moderno, que designa por "razão escolástica". Este conceito é proposto tardiamente, nas Meditações pascalianas, onde Bourdieu faz o balanço de décadas de investigação empírica (Bourdieu, 1997/1998).

\section{Fragmento 2: Pierre Bourdieu}

"Se a noção de universalidade (l'universel) avança, é porque existem microcosmos sociais que, apesar da sua ambiguidade intrínseca, ligada ao seu fechamento no privilégio e no egoísmo satisfeito de uma separação estatutária, são o lugar de lutas nas quais o que está em jogo é a noção de universalidade e nas quais os agentes, tendo, em medidas diferentes, segundo as suas posições e trajectórias, um interesse particular na universalidade, na razão, na verdade, na virtude, se empenham com armas que não são outra coisa senão as conquistas mais universais de lutas anteriores. Desta forma, os juristas, que (...) inventaram o Estado, puderam criar, verdadeiramente $e x$ nihilo, todo um conjunto de conceitos, de procedimentos e de formas de organização próprias a servir o interesse geral, o público, a coisa pública, na medida em que, fazendo isto, se faziam a si próprios, enquanto detentores ou depositários dos poderes associados ao exercício da função pública, e na medida em que podiam, desta maneira, garantir-se a si próprios uma forma de apropriação privada do serviço público, baseada na instrução e no mérito, e já não no nascimento. (...) a ascensão luminosa da razão e a epopeia emancipatória coroada pela Revolução francesa (...) tem um reverso obscuro, a saber a subida progressiva dos detentores do capital cultural, e em particular dos juristas" (Méditations pascaliennes, Paris, Seuil, 1997, pp. 146-7).

A razão escolástica é um produto de determinados habitus, caracterizados pelo distanciamento em relação à situação presente e pelo recurso à categoria de universalidade. Estes habitus, por sua vez, resultam da diferenciação de determinados campos $^{6}$. Estes campos - trata-se, em particular, dos campos da ciência (Bourdieu, 2001) e do direito (Bourdieu, 1986/1989) - diferenciaram-se pela competição que se gerou entre os agentes que participaram na sua formação. Estes agentes tinham como motivo a procura de um maior reconhecimento da sua capacidade de distanciamento e de mobilização da categoria de universalidade, o que quer dizer que tinham cada um "um interesse particular na universalidade" (Bourdieu, 1993/1997, pp. 146/107). Finalmente, estes habitus e a vocação destes campos correspondiam aos interesses dos poderes políticos, que necessitavam de especialis-

\footnotetext{
${ }^{4}$ Numa fase anterior de preparação deste texto, procurei construir um denominador comum entre os autores através da noção de efeito simbólico. No caso de Luhmann, este efeito reside, precisamente, na concretização destas distinções pelo sistema jurídico, distinções que poderão ter incidências sobre diversos domínios da actividade social.

5 O estilo de escrita e de construção teórica de Luhmann tem como consequência que as definições conceptuais se encontram dispersas em numerosos textos. Para uma orientação mais detalhada nesta obra, permito-me remeter para Guibentif (2005).

${ }^{6}$ A razão escolástica pode assim ser considerada como um efeito simbólico, nomeadamente, do habitus e do campo jurídico.
} 
tas em matéria científica e jurídica para consolidar a sua própria posição social, na forma do que chamamos hoje o Estado (Bourdieu, 1989).

A razão escolástica assim identificada "desencanta-nos" por dois motivos. Por um lado, como na interpretação de Luhmann, porque não resulta apenas de um esforço consciente e determinado em alcançar um melhor conhecimento do mundo (Bourdieu não nega um tal esforço, apenas quer chamar a atenção para o seu "reverso obscuro": Bourdieu, 1993; 1997, pp. 147/107). É também um efeito de relações de poder, da complexidade do mundo social. Por outro lado, e este é um argumento específico em Bourdieu, porque, emanando de um habitus caracterizado pelo distanciamento em relação as situações concretas, não nos fornece linearmente categorias adequadas à prática quotidiana.

\section{Jürgen Habermas}

Como era de esperar, é em Habermas que encontramos a interpretação mais próxima da dos autores iluministas; ou seja, a representação mais encantada da razão jurídica. Dito isto, também Habermas adquire a convicção, ao reconstituir o papel do direito nas sociedades modernas, que a razão, isto é, os meios semânticos de dominarmos a nossa história, não pode resultar directamente de um sujeito individual. É bem conhecido um dos passos no raciocínio pelo qual procura ultrapassar esta visão subjectivista: a razão não advém de um sujeito, advém da comunicação, da discussão entre sujeitos, que, aliás, se constituem nesta discussão. Mas neste primeiro passo, Habermas raciocina à escala da interacção.

Todo o interesse que Habermas passa a dedicar, a partir dos anos 80, ao direito (ver fragmento 3 ), deriva da preocupação em identificar melhor quais são as condições susceptíveis de favorecer um processo de comunicação com potencialidades equivalentes à escala de grandes sociedades e de sociedades complexas. Ou seja, como conceber uma comunicação à escala de grandes sociedades, que possa conduzir a um domínio efectivo por aqueles que discutem sobre a sua realidade, sobre a sua história. Nesta perspectiva, leva a cabo uma aprofundada confrontação entre os resultados dos seus trabalhos sociológicos e filosóficos e a experiência que os juristas têm do funcionamento das instituições. Um dos resultados deste trabalho - uma das principais teses de Facticidade e Validade (1992; 1996) - pode ser resumido da seguinte maneira: a comunicação, nas sociedades modernas, permite que uma colectividade faça a sua história, isto é, se identifique e concretize projectos, se forem realizadas duas condições: (1) devem existir dois âmbitos de comunicação distintos: por um lado, os procedimentos formais de tomada de decisão política e administrativa (o "sistema político constituído em estado de direito"; o "centro político": Habermas, 1992/1996: 527, 532s./437, 442); por outro lado, o universo de debates espontâneos (o "espaço público" - fala nesta obra muitas vezes de "espaços públicos" (plural) "autónomos", - “o poder comunicacional": ibidem); (2) tem que existir uma articulação entre estes dois âmbitos. Articulação que Habermas procura pensar, recorrendo nomeadamente à metáfora do cerco da comunicação espontânea aos procedimentos formais (Habermas, 1989, p. 52; 1992/1996: 533/442) ${ }^{7}$.

\section{Fragmento 3: Jürgen Habermas}

"A teoria comunicacional da sociedade entende o sistema político constituído em estado de direito como um entre vários sistemas de acção. Este sistema pode, se necessário, oferecer garantias em casos de problemas de integração da sociedade no seu conjunto, (...) na condição de estar enraizado (eingebettet) nos contextos da Lebenswelt pelo meio de um espaço público que se fundamente na sociedade civil." (Faktizität und Geltung, 1992, p. 527 s.)(...) o espaço público político não é apresentado apenas como antecâmara do aparelho parlamentar, mas sim como a periferia impulsionadora que cerca o centro político. Gerindo argumentos normativos, esta periferia, sem assumir intenções de conquista, tem efeitos sobre todas as partes do sistema político. Pelo meio de eleições gerais e de formas especiais de participação, as opiniões públicas transformam-se num poder comunicacional que autoriza o legislador e legitima uma administração reguladora, enquanto a crítica jurídica, publicamente mobilizada, obriga os tribunais, que intervêm na formação do direito, a um esforço mais rigoroso de justificação." (Faktizität und Geltung, 1992, p. 532 s.). 


\section{Michel Foucault}

Michel Foucault fala pouco, e sobretudo em termos irónicos, da razão, fala muito, em contrapartida, de sujeitos, principalmente nos anos 1980. Foucault chega à sua concepção do sujeito após um longo percurso. Em 1981, dedica as suas aulas no Collège de France à hermenêutica do sujeito (Foucault, 2001).

Começa pela crítica dos dispositivos de poder, da História da loucura na Idade clássica (1961/ /1972) a Vigiar e Punir (1975) (ver fragmento 4). $O$ poder exercer-se-ia cada vez mais pela forma como são observadas e reguladas as condutas individuais e o indivíduo, devidamente localizado, submetido a rotinas de cumprimento das regras, torna-se mais controlável, mas ao mesmo tempo, também, mais indivíduo. Nós, sujeitos, não passaríamos - esta é a conclusão da primeira etapa no trabalho de Foucault - de efeitos de poder, sujeitos que resultam de mecanismos de "sujeição" (assujetissement).

O sujeito que resulta da sujeição emerge, por definição, não como emancipado, mas sim como, por assim dizer, vigiando-se a si próprio. Pode, no entanto, haver um esforço específico de negação desta missão de auto-observação, isto é, de redefinição da relação consigo próprio. Foucault centra-se neste tema nos seus últimos anos, recorrendo nomeadamente a esta palavra curiosa: "Il faut se déprendre de soi-même." "É necessário desprender-se de si próprio". Será na prática deste "desprender", desta redefinição, e não somente no cumprimento das instruções dos dispositivos do poder, que surge o sujeito; que "os indivíduos concretos podem efectivamente reconhecer-se como sujeitos" (Foucault, 1984b/1994, p. 646; ver também 1982/1994, p. 232; 1984a/1994) ${ }^{8}$.

\section{Fragmento 4: Michel Foucault}

"Num regime disciplinar, a individualização é, por assim dizer, descendente. À medida que o poder se torna mais anónimo, aqueles sobre quem o poder se exerce tendem a ser mais fortemente individualizados; e exerce-se por vigilâncias mais do que por cerimónias, por observações mais do que por narrativas comemorativas, por medidas comparativas que têm a 'norma' como referência, e não por genealogias que apresentam antepassados como marcos de orientação, por 'desvios' mais do que por grandes feitos. (...) $\mathrm{O}$ momento em que se passou de mecanismos histórico rituais de formação da individualidade para mecanismos científico-disciplinares, substituindo o homem memorável pelo homem calculável (...), momento em que as ciências do homem se tornaram possíveis, é o momento em que é accionada uma nova tecnologia do poder (...). De facto, o poder produz; produz realidade (...) $\mathrm{O}$ indivíduo e o conhecimento que se pode ter dele fazem parte desta produção." (Surveiller et punir, 1975, pp. 194-6) "Creio que o direito penal faz parte do jogo social (...). Quer isto dizer que os indivíduos que fazem parte desta sociedade têm que reconhecer-se como sujeitos de direito que, nesta qualidade, são susceptíveis de serem punidos e castigados se infringem uma determinada regra. Nada de escandaloso. Mas o dever da sociedade é fazer com que os indivíduos concretos possam efectivamente reconhecer-se como sujeitos de direito." ("Punir, mon beau souci", 1984, Dits et écrits, vol. IV, pp. 645-6)

\section{Um quadro teórico derivado}

dos autores comparados: agir vs. instâncias

Passo agora a uma segunda operação de comparação, em que me vou distanciar mais das obras a comparar, e recorrer a referências gerais que pretendem transcender este conjunto de obras. Como anunciado, chamarei a ferramenta que vou utilizar um "quadro teórico", dando a esta expressão um sentido técnico específico: trata-se não de uma teoria (já insisti neste ponto: não procuro encontrar uma teoria que integre os elementos das outras), mas de uma grelha, destinada a situar teorias umas em relação às outras e, mais ambiciosamente, a situar teorias em relação à realidade social.

A construção deste quadro assenta em duas presunções. A primeira é a seguinte: as teorias sociológicas que estão hoje à nossa disposição têm bases sólidas pois resultam de intensas discussões críticas, de trabalho incidindo sobre abundantes observações e, em certos casos, da confrontação com experiências concretas de acção em vários domínios. Apresentam, assim, o que poderíamos

${ }^{8} \mathrm{O}$ sujeito seria um efeito simbólico diferido, indirecto, dos dispositivos - tecidos nomeadamente pelo direito - de poder. 
chamar "garantias de pertinência". Verificamos, no entanto, que estas teorias, embora beneficiando de "garantias de pertinência" comparáveis, divergem em pontos essenciais. Face a estas divergências, e face a estas "garantias de pertinência" comparáveis, vale a pena procurar explicações que não consistam, simplesmente, em dar razão a uma ou à outra. Parece preferível admitir o seguinte: a realidade social, irredutível a qualquer discurso singular, seria constituída de tal forma que, abordada sob perspectivas diferentes, exigiria interpretações diferentes e face a esta realidade, diferentes teorias sociológicas reconstruiriam diferentes "aspectos". O termo "aspecto" - em si nada original - reveste aqui um sentido preciso: não se trata de uma parte, de um componente, de um nível da realidade social; trata-se da realidade social na sua totalidade, mas abordada numa determinada perspectiva.

A segunda presunção, mais atrevida, é que poderá ser possível encontrar alguns "aspectos" dominantes na discussão sociológica contemporânea. Aspectos que corresponderão, sem necessidade de ajustamentos forçados, aos aspectos construídos por uma grande parte das teorias sociológicas existentes. Com efeito, a comparação dos autores aqui seleccionados e o confronto dos resultados desta comparação com os trabalhos de outros autores, conduz-me à identificação de dois, e apenas dois "aspectos". Dois aspectos nada inesperados, e que já muitas vezes ouvimos referidos, no entanto, em termos diferentes, e, talvez, com pressupostos ou subentendidos diferentes ${ }^{9}$. Dois aspectos, aliás, nada fáceis de nomear adequadamente. Adoptarei aqui a seguinte terminologia: o "agir" e as "instâncias".

Sob o aspecto das "instâncias", vemos a realidade social como composta por âmbitos, de natureza diversa, onde se processam actividades ${ }^{10}$, de natureza diversa. Uma questão importante sob este aspecto é a da inteligibilidade. Quem diz "actividade" - poder-se-ia também dizer operações, funcionamento, etc. - diz que determinados gestos ou signos são delimitáveis e identificáveis. $\mathrm{O}$ que faz que possam compor uma actuação mais complexa ou suscitar reacções apropriadas. Certas "instâncias" são claramente delimitadas, identificadas, e estruturadas por disposições explícitas, são as que correspondem ao que autores como Parsons ou Luhmann têm chamado de "sistemas" - ou "subsistemas" sociais. São também as "organizações".

Obviamente, a realidade social não se esgota em sistemas diferenciados e em organizações formais. Encontramos outras "instâncias" que, em abstracto, se deixam definir mais facilmente pela negativa: por um menor grau de diferenciação. Podemos pensar em "famílias", em "turmas". Mas devemos também pensar - e aqui adopto uma leitura que talvez possa surpreender - no que Erving Goffman chama a "ordem da interacção" (Goffman, 1981), isto é, aqueles âmbitos onde nós nos movemos na proximidade física dos nossos semelhantes, mantendo relacionamentos socialmente variáveis com os que cruzamos, gerindo-os como relacionamentos de indiferença, de atenção educadamente distante, de proximidade calorosa, etc.

Sob o aspecto do "agir", vejo em primeira linha "sujeitos" ou "actores", individuais ou colectivos. Uma questão importante sob este aspecto é a dos relacionamentos: os "sujeitos" e "actores", necessariamente, surgem em relação uns com outros. Estas relações podem ter significados diferentes, nomeadamente de solidariedade ou de oposição, e são, neste sentido, geradoras de forças (de atracção, repulsão, agressão, etc.). Destacam-se mais nitidamente duas realidades: agrupamentos que foi possível delimitar considerando a força dos vínculos que existem entre os seus elementos, e, fenómeno muito diferente, conflitos, identificando claramente protagonistas que se opõem uns aos outros. Estes agrupamentos e estes conflitos actualizam-se, em particular, em acções, definidas não apenas por referência a quadros gerais de inteligibilidade, mas por referência a uma situação concreta e a um actor concreto. Pode aliás assistir-se a processos complexos de construção recíproca entre acções, situações e actores.

O conceito de "individuação" (Neves, 2005) poderá desempenhar, na abordagem da realidade

\footnotetext{
9 Entre muitas distinções comparáveis, deve referir-se, destinada precisamente à teorização do direito na sociedade, a distinção entre regulação e emancipação (Santos, 2002).

${ }^{10}$ Ideal seria evitar a proximidade linguística entre as palavras "agir" e "actividade", que pode prejudicar a distinção dos dois aspectos. Mas as conotações das duas palavras vão ao encontro do que se pretende aqui expor. Que seja próximas, aliás, não é de admirar: estamos sempre a falar de dois aspectos de uma mesma realidade.
} 
social sob o aspecto do "agir", um papel análogo ao papel do conceito de "diferenciação" na abordagem das instâncias. Também sob o aspecto do "agir", a realidade social não se esgota no que é mais visível por ser mais "individuado". Deveremos reconhecer lugares ou momentos onde o que "se age" não se deixa facilmente atribuir a alguém em particular, nem a uma intenção claramente enunciada.

O quadro teórico construído na base desta distinção (ver gráfico 1, no final do texto) actualiza uma certa concepção da realidade social e da sociologia. A realidade social é abordada com dois grandes pressupostos que de alguma maneira se cruzam. Em primeiro lugar, caracteriza-se por poder ser abordada sob estes dois aspectos distintos: o "agir", aspecto das forças, dos movimentos, dos sujeitos, dos conflitos e as "instâncias", aspecto dos funcionamentos, dos gestos coordenados. Em segundo lugar, sob estes dois aspectos, a realidade apresenta-se como composta por elementos mais "construídos", mas também, para além destes elementos, por um mundo de fenómenos mais difusos. Ou seja, mais precisamente: sob o aspecto do "agir", podem ser menos ou mais individuados sob o aspecto das instâncias, menos ou mais diferenciados. A sociologia, no estado actual do seu desenvolvimento, oferece teorias que podem contribuir poderosamente para a reconstituição de fenómenos sociais específicos enquanto abordados sob um ou outro destes dois aspectos. Estas teorias têm que ser aproveitadas e desenvolvidas para cada uma das duas abordagens. Quando abordamos fenómenos concretos - aqui, o direito -, valerá a pena - mas depois de devidamente aproveitadas as potencialidades interpretativas das teorias existentes - avançar na reflexão sobre as correspondências que podem existir entre as observações recolhidas sob cada um dos dois aspectos.

As vocações deste quadro teórico são, mais especificamente, as seguintes:

$\Rightarrow$ facilitar a caracterização e comparação de diferentes teorias sociológicas;

$\Rightarrow$ facilitar a caracterização e comparação de conceitos elaborados no âmbito destas teorias, de forma a poder, com conhecimento de causa, isto é, sem perder de vista o seu estatuto originário, retrabalhá-los;
$\Rightarrow$ facilitar a reconstrução de objectos teóricos específicos face a terrenos concretos, e a elaboração de instrumentos de observação e de interpretação que possam tirar proveito em boas condições das teorias disponíveis (será tratado na terceira secção do presente ensaio).

Vou ilustrar estas vocações. Nesta parte, vou aplicar o quadro teórico às teorias e aos conceitos dos autores que seleccionei. Na terceira parte, esboçarei a aplicação no trabalho empírico.

Mas antes de abordar estas vocações, queria tecer algumas reflexões sobre as fontes de inspiração deste quadro. Embora deva muito ao estudo dos quatro autores aqui comparados, outras leituras e experiências de investigação tiveram um papel importante.

A noção de teorias que, ao mesmo tempo, apresentam um grau comparável de pertinência, e se contradizem, surgiu à medida que avancei na descoberta dos pensamentos de Habermas e Luhmann. A obra de Luhmann convenceu-me da pertinência de um questionamento da realidade social que faça abstracção dos sujeitos. Mas a distinção adoptada também se encontra em Foucault, que aborda, sucessivamente, os dois aspectos. A distinção proposta revelou-se ainda mais necessária quando tive que fazer, em relação aos meus ensinos a juristas, um balanço geral da realidade social abrangida pelos quatro autores tratados (a minha preocupação era saber se estes quatro autores dão acesso a uma "amostra representativa" de temas sociológicos). Tive o cuidado de confrontar este balanço com outros balanços gerais da disciplina, em particular o manual de Anthony Giddens (Giddens, 1993). Esta confrontação revelou que, globalmente, os autores aqui comparados davam pouca visibilidade às noções de conflito e de acção. Esta constatação levou-me a aprofundar, nomeadamente, a obra de Alain Touraine. Este autor sempre concedeu uma posição apenas marginal ao direito nos seus objectos de reflexão; daí que seja menos citado em trabalhos socio-jurídicos (algo que acaba de mudar, com o seu último livro, Um novo paradigma [2005]). Alain Touraine adopta uma posição diametralmente oposta à de Luhmann: quer entender o "agir", quer entender como surgem actores, sujeitos, na tomada de consciência da sua acção e da sua força e deixa a outros - subentendendo-se, a Pierre Bourdieu - 
as visões do social que enfatizam o que faz actuar agentes, o que define a sua actividade para além da sua própria vontade.

Devo aqui sublinhar um ponto: a intensidade das tensões que separam teorias como as de Luhmann e Habermas, ou Bourdieu e Touraine, ou a amplitude da viragem no percurso de Foucault, devem ser elas próprias tidas em conta. Impõe-se o seguinte raciocínio: os dois aspectos delimitados devem ser concebidos numa relação ela também de tensão, isto é, simultaneamente, de articulação necessária e de incompatibilidade. Aliás, esta tensão, se pensarmos bem, é o grande tema dos quatro autores: a razão desencantada. $\mathrm{O}$ que é a razão? É a capacidade de agir como sujeito em contextos estruturados, isto é: de conciliar os dois aspectos da realidade social. O desencanto? Quando se verifica que esta capacidade apenas se alcança a um custo muito mais elevado do que se esperava; muito mais elevado do que o admitia Kant, em particular no seu texto "Was ist Aufklärung?"

Entre as experiências que vieram reforçar a convicção de que se deveria valorizar a distinção aqui defendida, apenas assinalaria mais uma. Num projecto de análise comparada das políticas sociais no espaço europeu, tivemos que abordar o papel de determinados "actores" (Wehner et al., 2005). Na discussão dos nossos conceitos e observações, tornou-se nítida a necessidade de abordar tais "actores", tanto na perspectiva do seu "agir" (sujeitos, individuais e colectivos, que se afirmam, adquirem força, em conflitos e jogos de alianças), como na perspectiva das instâncias que definem estatutos formais, também estes, mas de maneira radicalmente diferente, constitutivos de papéis, papéis cujo desempenho faz a realidade dos processos formais de negociação, avaliação, etc.

\section{Caracterização global das teorias comparadas}

Já ficou dito: Luhmann limita-se às instâncias. Pode aliás acrescentar-se que, no seu trabalho, dá prioridade as instâncias diferenciadas, e sabe-se que, entre estas, privilegiou os sistemas sociais funcionalmente diferenciados. Entre os outros sistemas sociais, o tema que Luhmann mais aprofundou, para além da sociedade no seu conjunto (Luhmann, 1997a, 1997b), é o das organizações (Luhmann, 2000a) onde abriu pistas de reflexão muito estimulantes sobre a sua articulação com os sistemas funcionalmente diferenciados. Luhmann só não chegou a publicar o volume que eu sonharia ter lido: As interacções da sociedade (mas existem longos capítulos em Sistemas sociais, de 1984 e em A sociedade da sociedade, de $1997^{11}$ ).

Quanto a Michel Foucault poder-se-á dizer, em termos simplificadores, que dedicou uma metade do seu percurso às instâncias; outra aos sujeitos. No entanto, o seu pensamento sobre os sujeitos, na segunda etapa, é profundamente marcado pelas reflexões anteriormente elaboradas sobre os dispositivos e discursos.

O trabalho de Habermas é mais difícil de situar. Mas eu defenderia a seguinte esquematização. Habermas produz uma obra pela qual pretende, assumidamente, contribuir para as ciências sociais: trata-se da Teoria do agir comunicacional (Habermas, 1981;1987a). É nesta obra que discute a célebre oposição entre sistemas e Lebenswelt (Habermas, 1981;1987b). Esta oposição merece ser lida como uma contribuição para uma leitura da realidade social enquanto universo de instâncias mais aberta do que a leitura proposta por Luhmann. Com efeito, a Lebenswelt é abordada, pelo menos também, muito sob a inspiração de Mead, como uma instância da realidade social, uma instância tecida não por actividades formalizadas, mas por gestos quotidianos, que têm um sentido sempre já experienciado no momento em que o procuramos formular. A própria terminologia de Habermas, na Teoria do agir comunicacional, vai no sentido desta interpretação: procura reconstituir como se "diferenciaram", na modernidade, os "componentes estruturais" da Lebenswelt (Habermas, 1981, vol. 2, p. 214). Resumindo: Habermas, enquanto sociólogo, aborda as instâncias. Porém, como sabemos, não se limita às instâncias pois toda uma vertente da sua obra procura reconstruir o "agir", conceptualizado-o em termos de "comunicação". Mas este trabalho, Habermas aborda-o identificando-se não como sociólogo, mas como filósofo. Um filósofo que se dedica à ética da discussão, pretendendo entender e fundamentar uma comunicação da qual possa

\footnotetext{
${ }^{11}$ Ver Luhmann, 1984/1995, cap. 10; 1997a, pp. 813 ss.
} 
emergir razão partilhada por sujeitos (Habermas, 1991). Um filósofo que se aproxima do objecto direito pretendendo entender e fundamentar uma comunicação jurídica da qual possa emergir uma razão susceptível de ser partilhada por sujeitos que teriam uma experiência comum do seu país, continente ou mundo (Habermas, 1992/1996; Habermas, 2001, Habermas, 2005b).

Bourdieu, em contrapartida, resiste à distinção proposta. Mas resiste justificando explicitamente esta opção, reconhecendo portanto, de alguma forma, a pertinência da distinção. É precisamente esta resistência que se exprime na sua revindicação de um lugar que não seja nem subjectivista (recusando a herança de Sartre), nem estruturalista (Bourdieu, 1985/1989, p.61). Recordemos um motivo, entre outros, que poderá ter tido de adoptar esta posição: dos autores aqui comparados, é o que mais se tem envolvido no trabalho de campo. Poder-se-á dizer que, mais próximo da realidade social, Bourdieu sentiu maior necessidade em contemplar sempre os seus dois aspectos.

\section{A constelação dos conceitos}

O quadro teórico que se acaba de esboçar permite, também, compor um mapa dos conceitos propostos pelos autores comparados. Qual é a utilidade de um tal mapa? Resumindo, diria que permite situar cada conceito numa problemática ampla, ligada às problemáticas específicas das teorias comparadas, sem que o pensamento do investigador que constrói o mapa seja directamente condicionado por estas teorias. E permite recomposições conceptuais na abordagem do terreno, eventualmente recorrendo a vários autores; salvaguardando, apesar da diversidade das fontes, a coerência do instrumento de observação, pela referência à grande perspectiva de abordagem do terreno pela qual se optou. Poderia dizer-se que o quadro teórico, como entendido aqui, estabelece o que se poderia chamar um "loose coupling" entre as teorias e o trabalho empírico.

Começando pela abordagem das "instâncias", registo em primeiro lugar a riqueza e a pertinência dos conceitos elaborados por Luhmann - e desen- volvidos entretanto por vários outros autores - para a abordagem empírica de âmbitos diferenciados de actividade social, enquanto realidades "auto-poiéticas", isto é, actividades que se dão as suas condições de possibilidade pela sua própria continuação prática. Trata-se, em particular, dos sistemas funcionais e das organizações. Luhmann também desenvolveu todo um universo de conceitos que se articulam com estes e que podem traduzir-se em instrumentos de observação. Apenas recordaria o conceito de “código" (Luhmann, 1993, pp. 165 ss.), a distinção que identifica um sistema e que se reproduz na sua auto-poiése; um conceito com grandes potencialidades, nomeadamente para a análise de discursos (Guibentif, 2001).

Poder-se-á procurar articular com estas linhas de trabalho os conceitos de discurso e de dispositivo de Michel Foucault (quaisquer que sejam as reservas de Luhmann a este respeito).

Em complemento a estas conceptualizações, dever-se-ão desenvolver tipologias de instâncias que permitam a abordagem do que poderíamos qualificar de instâncias menos diferenciadas. Luhmann, neste ponto, recusaria esta noção de instância menos diferenciada e diria provavelmente que uma instância existe, porque se diferenciou, ou então não existe. Mas também admite que pode haver processos múltiplos e rápidos de diferenciação e de desdiferenciação e até propõe um conceito para âmbitos onde são possíveis tais processos. Este tipo de realidade é designado, nos seus últimos trabalhos, de medium (Luhmann, 2000b, p. 287).

Vale a pena procurar, inspirados pela nossa experiência diária e histórica, contextos onde tais diferenciações-desdiferenciações, de instâncias de uma natureza algo específicada, se tornaram mais prováveis. Já referi a Lebenswelt de Habermas na Teoria do agir comunicacional. A Lebenswelt remete para o dia-a-dia do sujeito moderno no contexto em que foi socializado. É a instância onde o sujeito experiencia permanentemente o carácter óbvio de certas ferramentas de comunicação, logo o carácter óbvio de certas actividades pelas quais se encontra associado a outros ${ }^{12}$.

Mais recentemente, Habermas tem sentido a necessidade de admitir a existência de âmbitos de

\footnotetext{
12 Note-se que o quadro teórico aqui proposto poderá contribuir para uma melhor distinção, na análise da obra de Habermas, entre os conceitos de Lebenswelt e de agir comunicacional.
} 
experiência mais especificamente definidos. Âmbitos de experiência ligados ao facto de existirem sistemas e de o funcionamento destes sistemas criar experiências partilhadas. $\mathrm{O}$ conceito mais importante que avançou a este respeito é o de "solidariedade cidadã", staatsbürgerliche Solidarität (Habermas, 2001; 2005a/2004). Este conceito, na verdade, apenas merece da parte de Habermas definições implícitas, mas o que os exemplos citados sugerem respeita mais ao que poderemos legitimamente chamar uma instância: uma prática das instituições, de alguma regularidade, que já não necessita de ser actualmente justificada, e que nos facilita, em âmbitos específicos, a interacção com os outros. Habermas também refere, como fenómenos análogos, os âmbitos onde se vivem as experiências de utentes da administração, ou de consumidores no domínio económico.

Quanto à abordagem do "agir", o conceito mais óbvio, como já referi, está quase ausente dos quatro autores aqui comparados. Seria o conceito de actor, defendido por Alain Touraine (não posso deixar de assinalar que o próprio Touraine se mostra hoje menos radical na defesa deste conceito do que em trabalhos anteriores). Encontramos, em contrapartida, os sujeitos, na obra de Foucault, e deveremos admitir que a discussão (Diskurs), tal como teorizada por Habermas, é uma prática na qual se actualizam sujeitos, embora necessariamente no plural (Habermas, 1991).

Colocaria deste lado do quadro, embora consciente das limitações inerentes a esta opção, o conceito de campo de Bourdieu (Bourdieu, 2001, p. 67 ss.). Tomo assim em conta, aliás, a insistência do próprio Bourdieu em distinguir este conceito do conceito de sistema de Luhmann (Bourdieu, 1986; 1989, p. 211). Um campo delimita actividades especializadas e, neste sentido, corresponde ao que chamamos aqui uma instância. Mas o que Bourdieu pretende captar é o processo de "individuação" deste campo, a maneira como este campo se impõe no mundo social, pela consciência partilhada que têm os agentes envolvidos de jogar um mesmo jogo. E, sobretudo, o que o interessa não são, em primeira linha, os códigos que dão unidade à actividade dos agentes; são, antes de mais, as relações de força que, ao estabelecerem-se, identificam os agentes ao mesmo tempo que o próprio campo.

Prolongando o trabalho de conceptualização neste aspecto, convirá referir uma expressão de Foucault, que fascinou em particular Antonio Negri ${ }^{13}$. Segundo a última frase de Vigiar e Punir, onde Foucault - é esta a leitura sugestiva de Negri - já esboça o programa de trabalho que o levará à hermenêutica do sujeito, deveremos estar atentos, para além dos dispositivos de poder e das práticas disciplinares, ao mundo de reacções a estas práticas, difusas, mal formuladas, mas originando forças. Estas forças, Michel Foucault designa-as pela expressão "le grondement de la bataille" (Foucault, 1975, p. 315).

E, muito além dos sujeitos, além dos conflitos e das batalhas, haverá algum "agir"? Eu diria que a ambição de Bourdieu, com o conceito de "habitus", foi agudizar a nossa atenção precisamente face a esta região do aspecto "agir", uma região na qual a "razão escolástica" tem dificuldades em penetrar. É verdade que o habitus é concebido como estruturado, e pode contribuir para a estrutura de determinadas instâncias de relacionamento social. Mas Bourdieu, com este conceito, também pretende captar o agir actual, com a sua materialidade, irredutível à simples actualização de estruturas sociais. Neste sentido, aproxima-se de certas referências de Habermas ao agir comunicacional. Dito por outras palavras, escapar-nos-ia muito da realidade social, se não estivéssemos atentos a todo um mundo de gestos e palavras, que "se dão" sem que, no momento, seja claro ou necessário esclarecer a quem devem ser atribuídos; que poderão ser abordados como cumprindo rituais, rotinas, instruções, etc., mas que não deixam de ter uma actualidade e uma materialidade próprias. Actualidade e materialidade que constituem a matéria-prima de qualquer processo de individuação, ou de génese de forças.

\section{Aplicação no trabalho empírico}

Quais as orientações que este quadro teórico poderá fornecer ao trabalho empírico? Pode inspirar

${ }^{13}$ Conferência de Antonio Negri realizada em Lisboa no Instituto Franco-Português, em Novembro de 2005, no âmbito do colóquio "Michel Foucault: Lei, segurança e disciplina. Trinta anos depois de Vigiar e Punir". Ver também Hardt/Negri, 2004. 
interrogações. Alguns dos elementos acima expostos poderão ter dado uma noção desta potencialidade que, portanto, não aprofundarei aqui. Para além disto, este quadro teórico pode constituir o pano de fundo para a reconstituição do objecto a investigar, e podem ser derivadas dele indicações para a condução do trabalho empírico.

\section{Aplicação do quadro teórico na construção do objecto de investigação}

O quadro teórico proposto oferece uma base para o trabalho de construção do objecto. Vejamos como isto resulta no caso do direito, considerado aqui em termos gerais (um raciocínio semelhante deverá ser conduzido na abordagem de outros objectos mais específicos de investigação jurissociológica, em domínios mais específicos de actividade jurídica). O direito, como qualquer outro fenómeno social, deve ser abordado sob os dois aspectos, do "agir" e das "instâncias".

Começo pelas instâncias. Poderemos tomar como ponto de partida desta construção do objecto a existência de uma instância diferenciada - o "direito" - nas sociedades modernas, nisto seguindo Luhmann e Foucault. Sempre sob o aspecto das instâncias, poderemos reconstituir a realidade social do direito em termos de "cruzamentos" ou "interferências" entre esta e outras instâncias. Falando em cruzamentos, refiro-me ao seguinte fenómeno: o discurso jurídico enuncia-se, mais concretamente, em contextos específicos, estruturados não apenas pela "lógica jurídica", mas também por lógicas económicas, pedagógicas, etc., que criam as condições materiais de possibilidade desta enunciação. Trata-se, essencialmente, de instituições e profissões, ligadas à administração da justiça, ao ensino do direito, etc, isto é: o conjunto complexo de organizações que perfazem o que se convencionou chamar, entre juristas, os "sistemas jurídicos nacionais". Mas trata-se, também, de todo um mundo, mais difuso e movediço, de arenas de debate, de publicações, de dispositivos de consulta (que sofrem hoje rápidas e profundas transformações com o desenvolvimento da internet). Falando em interferências - palavra aqui utilizada como metáfora facilitando uma descrição sumária - refiro-me ao seguinte: toda a comunicação jurídica, que se processa concretamente nos âmbitos que se acaba de evocar, se prende com eventos ou actividades pertencentes a outras instâncias: em grande parte, a economia, mas também, e, cada vez mais, a ciência, ou ainda a arte, a gestão de organizações, etc.

O direito também pode ser abordado sob o aspecto do "agir". As suas disposições, as possibilidades de actuação dos organismos que o aplicam, podem ser aproveitadas por quem queira obter um determinado resultado. $\mathrm{Na}$ abordagem sob o aspecto do agir, dada a nitidez dos contornos que adquiriram as instâncias "sistemas jurídicos nacionais", valerá a pena fazer a hipótese de dois âmbitos de acção distintos, embora articulados entre si: o mundo jurídico, e o mundo social que o envolve. $\mathrm{O}$ direito poderá contribuir para a emergência de sujeitos neste mundo social envolvente, fornecer-lhes instrumentos e dar-lhes forças. Mas também constitui um âmbito no interior do qual se verificam (Bourdieu esteve particularmente atento a estes fenómenos) conflitos entre pessoas ou entidades envolvidas na prática do direito. Um dos desafios à investigação da realidade jurídica é entender como se articulam estes processos internos e externos.

\section{Implicações do quadro teórico para a condução do trabalho empírico}

Do quadro teórico apresentado também se podem derivar orientações para o trabalho empírico. Este deverá incluir três passos: (1) observar, sempre que possível, tanto sob o aspecto do "agir" como sob o aspecto das "instâncias", e procurar alcançar uma massa crítica de observações em relação aos dois aspectos; (2) avançar o mais possível na interpretação destas observações à luz das teorias existentes com vocação privilegiada para cada um dos dois aspectos; (3) tendo avançado nestas duas linhas de interpretação, procurar elaborar, quando e onde possível, interpretações susceptíveis de dar conta de fenómenos perceptíveis sob os dois aspectos, ou que, embora observados sob aspectos diferentes, parecem estar ligados. Limitar-me-ei, aqui, ao primeiro destes três passos.

Em muitas circunstâncias, dada a amplitude, a densidade e a complexidade do mundo jurídico, convirá começar pela abordagem das instâncias. Tratar-se-ia de reconstituir a configuração destas 
numa região particular da realidade social. Primeiro, devem recolher-se observações sobre actividades susceptíveis de serem atribuídas a várias instâncias. As observações recolhidas são depois tratadas, precisamente, no sentido de fazer surgir a diversidade das instâncias. Podem ser mobilizados os mais variados instrumentos de recolha de dados. Pode recorrer-se aos discursos produzidos na "região" a observar: discursos preexistentes ou recolhidos através de entrevistas. Face a estes discursos, a identificação das várias instâncias passará por uma análise das fontes, das "autorias", de eventuais "subconjuntos" no discurso. Passará depois por uma análise do próprio conteúdo, atenta, nomeadamente, às distinções mobilizadas, mas também, de maneira mais genérica, ao tipo de argumentos utilizados. Na identificação das instâncias, também se poderá ter em conta indicadores mais materiais: por exemplo disposições arquitectónicas ou urbanísticas. Ou ainda a configuração das redes e aplicações informáticas utilizadas no terreno observado.

A abordagem empírica do agir ${ }^{14}$ afigura-se mais difícil, porque o agir, por definição, tem os seus momentos e lugares e não deixa marcas tão visíveis como as instâncias na paisagem social, e também porque o agir observado pode, às vezes, ter apenas pouca relevância para a prática do direito. Aqui, o procedimento a privilegiar é, obviamente, a observação directa. Mas também as entrevistas aprofundadas podem revelar um agir: uma entrevista com um sociólogo pode ser uma ocasião, para uma pessoa envolvida numa determinada prática jurídica, de se assumir como sujeito desta prática. Finalmente, os discursos recolhidos poderão, também, revelar o agir pois, em certos casos, este emerge ao relatar acontecimentos que manifestaram a existência e a força de um interveniente, ou a intensidade de um conflito e noutros casos, porque se terá encontrado um texto pelo qual alguém - falando em termos breves - se tornou sujeito.

Ousaria, chegando ao termo deste ensaio, avançar um exemplo deste fenómeno, retirado da minha experiência pessoal. Fiz várias investigações, nomeadamente para um capítulo da minha tese de doutoramento (Guibentif, 1997), sobre o sistema português de segurança social, mais especificamente, sobre a sua história recente: os anos do pós-guerra. Como se sabe, a literatura nesta matéria é escassa, e muito do material existente emana de fontes oficiosas ou inspira-se muito directamente nestas fontes. Ao ler esta documentação, tive uma sensação muito peculiar: no meio de um mar de discursos assaz cinzentos, os textos de um autor em particular davam-me, literalmente, a sensação de entrar num espaço iluminado. Eram textos da autoria de António da Silva Leal ${ }^{15}$, já falecido quando realizei esse trabalho. $\mathrm{O}$ quadro teórico que apresento aqui oferece-me, anos mais tarde, uma interpretação sociológica desta sensação (ou - em termos mais simples - permite-me formulá-la melhor): este autor tinha - como nós aqui ainda nos lembramos - uma intensa vontade de contribuir, enquanto autor, à formação de uma cultura portuguesa de direito social, ou seja, estava animado, no mais forte sentido da expressão, pela vontade de agir. Agir pelos seus textos. Uma das mais belas ambições para a sociologia seria de se dar meios de melhor revelar manifestações de agir como estas, deixando intacta a sua força.

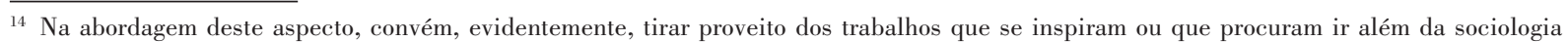
accionista de Alain Touraine. Em Portugal, em particular, Guerra (2002).

${ }^{15}$ Recordarei aqui apenas uma referência, mais próxima da sociologia: Leal, 1979.
} 


\section{Gráfico 1}

\section{Individuação}

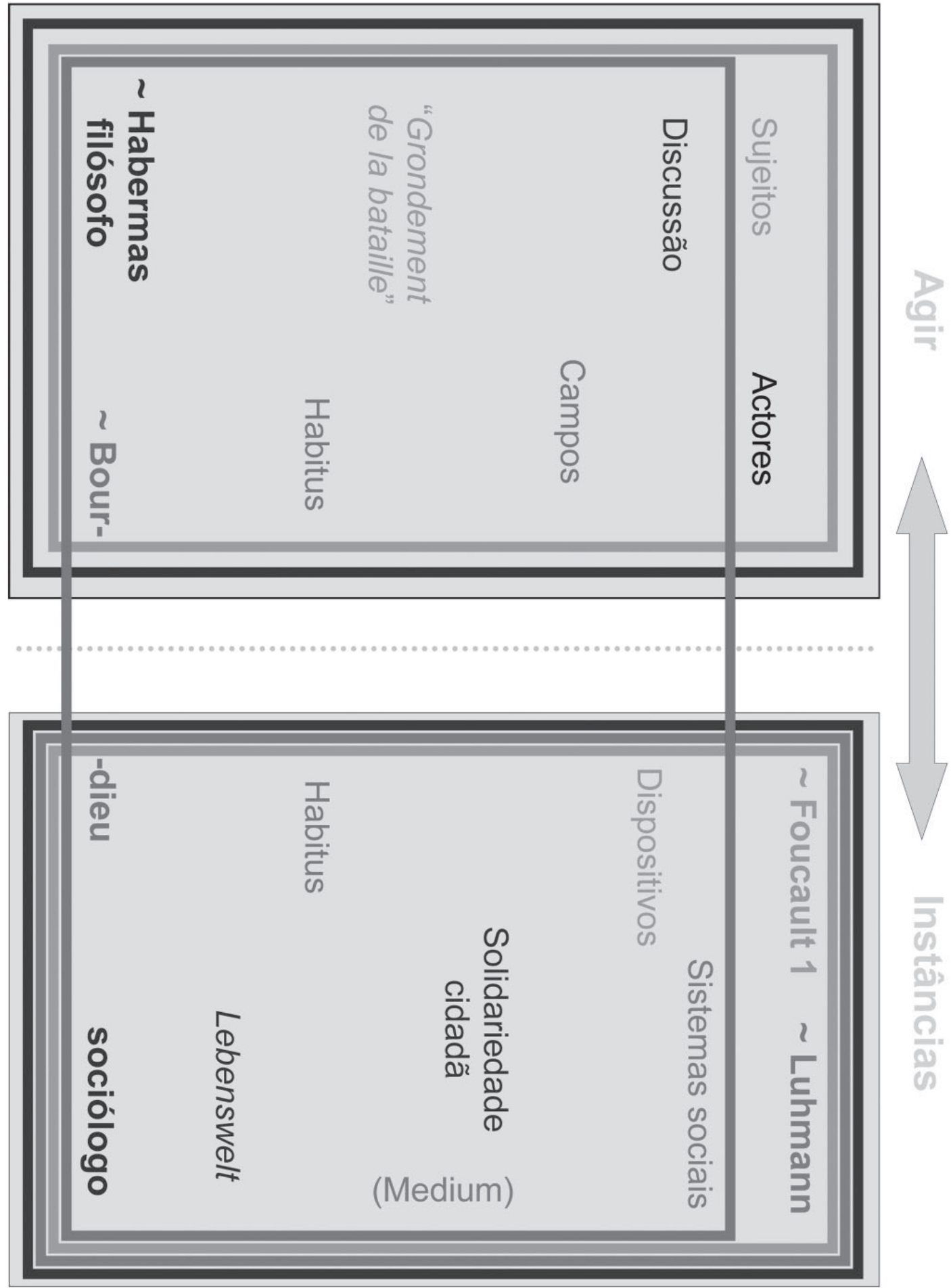

\section{Diferenciação}




\section{Referências}

Bourdieu, Pierre (1985/1989), "A génese dos conceitos de habitus e de campo", in: Id., O Poder Simbólico, Lisboa, Difel, 1989, pp. 209-254 (publ. orig.: "The genesis of the concepts of Habitus and Field" Sociocriticism, II/2, 1985, pp. 11-24). - (1986/1989), "La force du droit - éléments pour une sociologie du champ juridique", Actes de la recherche en sciences sociales $\mathrm{n}^{\circ} 64,1986$, pp. 3-19; trad. port.: "A força do direito", in: Id., O Poder Simbólico, Lisboa, Difel, 1989, pp. 209-254.

- (1989), La noblesse d'État, Paris, Minuit.

- (1993/1997), "Esprits d'Etat - Genèse et structure du champ bureaucratique", (publ. orig. em francês: Actes de la recherche en sciences sociale, 96/97, 1993, pp. 49-62; reeditado em Raisons pratiques, Paris, Seuil, 1994, pp. 99-133; traduzido em português: Razões práticas, Oeiras, Celta, 1997).

- (1997/1998), Méditations pascaliennes, Paris, Seuil, 1997 (trad. port.: Oeiras, Celta, 1998).

- (2001), Science de la science et réflexivité, Paris, Liber-Raison d'agir.

Fernandes, António Teixeira (2000), "Os direitos do homem na legitimação dos estados", Sociologia, 10, pp. 9-26.

Foucault, Michel (1961/1972), Histoire de la folie à l'âge classique, Paris, Gallimard, 1972 (ed. orig.: Paris, Plon, 1961).

- (1975), Surveiller et punir, Paris, Gallimard (trad. bras.: Vigiar e Punir, Petrópolis, Vozes, 1977).

- (1978/1979), "La gouvernementalité" (aula proferida em Fevereiro de 1978), Actes n $^{\circ}$ 54, pp. 6-15; versão port.: "A governamentalidade", in: Id., Microfísica do poder, Rio de Janeiro, Graal, 1979, pp. 277-293.

- (1982/1994), "Le sujet et le pouvoir", in: Id., Dits et écrits, Paris, Gallimard, pp. 222-243 (publ. orig.: in: H. Dreyfus, P. Rabinow (eds.), Michel Foucault. Beyond Structuralism and Hermeneutics, Chicago, University of Chicago Press).

- (1984a/1994), "Face aux gouvernements, les droits de l'homme", Libération, 30 juin-ler juillet 1984; republ. in: Id., Dits et écrits, Paris, Gallimard, 1994, vol. IV, pp. 707-708.

- (1984b/1994), "Qu'appelle-t-on punir?" (entretien avec Michel Foucault mené par F. Ringelheim), Revue de l'université de Bruxelles, 1984, no 1-3 (número temático: Punir, mon beau souci. Pour une raison pénale), republ. in: Id., Dits et écrits, Paris, Gallimard, 1994, vol. IV, pp. 636-646.

- (2001), L'herméneutique du sujet (cours au collège de France 1981-1982), Paris, Gallimard Seuil.

Giddens, Anthony (1993), Sociology, Cambridge, Polity Press (2. ${ }^{\mathrm{a}}$ edição).

GILISSEn, John (1979/1988), Introdução histórica ao direito, Lisboa, Fundação Gulbenkian, 1988 (ed. orig.: Bruxelles, Bruylant, 1979).

Goffman, Erving (1983), "The Interaction Order", American Sociological Review, 48, pp. 1-17.

Guerra, Isabel (2002), Fundamentos e processos de uma sociologia de acção. O planeamento em ciências sociais, S. João de Estoril, Principia.

Guibentif, Pierre (1997), La pratique du droit international et communautaire de la sécurité sociale - Etude de sociologie du droit de la coordination, à l'exemple du Portugal, Basileia/ Francoforte, Helbing \& Lichtenhahn.
- (2001), “A comunicação jurídica no quotidiano lisboeta. Proposta de abordagem empírica à diferenciação funcional", Forum Sociológico n ${ }^{0}$ 5/6 (II série), 2001, pp. 129$-161$.

- (2005), "O direito na obra de Niklas Luhmann. Etapas de uma evolução teórica", in Santos, José Manuel (org.), $O$ pensamento de Niklas Luhmann, Covilhã, Universidade da Beira Interior (Ta Pragmata), 2005, pp. 185-252.

HabERMAS, Jürgen (1963), "Naturrecht und Revolution" ("Direito natural e Revolução"), in Habermas, Jürgen, Theorie und Praxis. Sozialphilosophische Studien, Neuwied/Berlin, Luchterhand, 1963 (trad. fr. Théorie et pratique, Paris, Payot, 1975; trad. ingl. Theory and Practice, London, Heineman, 1974).

- (1981/1987a), Theorie des kommunikativen Handelns (2 vols), Francoforte, Suhrkamp, 1981 (trad. fr: Théorie de l'agir communicationnel, Paris, Fayard, 1987).

- (1981/1987b), "Tendências da Juridicização", Sociologia.

- Problemas e Práticas no 2, 1987, pp. 185-204 (tradução do capítulo "Tendenzen der Verrechtlichung", in Id., Theorie des kommunikativen Handelns, Francoforte, Suhrkamp, 1981, vol. 2, pp. 522-547).

- (1989), "La souveraineté populaire comme procédure Un concept normatif d'espace public", Lignes, $\mathrm{n}^{\circ} 7$, Setembro de 1989, pp. 29-58 (publ. orig.: "Ist der Herzschlag der Revogglution zum Stillstand gekommen?", in Forum für Philosophie Bad Homburg (Hg.), Die Ideen von 1789 in der deutschen Rezeption, Francoforte, Suhrkamp, 1989, pp. 7-36; reed. Habermas, 1992/1996, pp. 600-631/463-490).

- (1991), Erläuterungen die Diskursethik (Esclarecimentos sobre a ética da discussão), Francoforte, Suhrkamp.

- (1992/1996), Faktizität und Geltung. Beiträge zur Diskurstheorie des Rechts und des demokratischen Rechtsstaats (Facticidade e validade. Contribuições para uma teoria do discurso aplicada ao direito e ao Estado de direito democrático), Francoforte, Suhrkamp, 1992 (trad. ingl.: Between Facts and Norms, Cambridge, Polity Press, 1996).

- (2001), "Braucht Europa eine Verfassung?" (A Europa necessita de uma constituição?), in: Id., Zeit der Übergänge, Francoforte, Suhrkamp, pp. 104-129.

- (2005a/2004), "Vorpolitische Grundlagen des demokratischen Rechtsstaates", in: Jürgen Habermas, Joseph Ratzinger, Dialektik der Säkularisierung, Freiburg im Breisgau, Herder, pp. 15-37 (trad. francesa: "Les fondements prépolitiques de l'État démocratique", Esprit, Julho de 2004, pp. 6-18.

- (2005), "Eine politische Verfassung für die pluralistische Weltgesellschaft?" (Uma constituição política para a sociedade-mundo pluralista?), in: Id., Zwischen Naturalismos und Religion, Francoforte, Suhrkamp, pp. 324-365.

HaRdT, Michael, Negri, Antonio (2004), Multitude, London, Hamish Hamilton.

Hespanha, António M. (2004), Guiando a Mão Invisível. Direitos, Estados e Lei no Liberalismo Monárquico Português, Coimbra, Almedina.

LEAL, António da Silva (1979), "Os grupos sociais e as organizações na Constituição de 1976 - A rotura com o corporativismo", in: MirandA, Jorge (org.), Estudos sobre a Constituição, vol. 3, Lisboa, Petrony, pp. 195-353. 
Luhmann, Niklas (1967), "Soziologische Aufklärung", in: Id., Soziologische Aufklärung 1, Opladen, Westdeutscher Verlag, 1970, pp. 66-91 (publ. orig.: Soziale Welt 18, 1967, pp. $97-$ 123; tradução portuguesa em Santos, José Manuel [org.], $O$ pensamento de Niklas Luhmann, Covilhã, Universidade da Beira Interior [Ta Pragmata], 2005).

- (1984/1995), Soziale Systeme, Francoforte, Suhrkamp, 1984 (trad. ingl.: Social Systems, Stanford, Stanford University Press, 1995)

- (1993/2004), Das Recht der Gesellschaft, Francoforte, Suhrkamp, 1993 (trad. ingl.: Law as a Social System, Oxford, Oxford University Press, 2004).

- (1997a), Die Gesellschaft der Gesellschaft (A sociedade da sociedade), Francoforte, Suhrkamp.

- (1997b), "Globalisation ou société du monde: comment concevoir la société moderne?", in: D. Kalogeropoulos (dir.), Regards sur la complexité sociale et l'ordre légal à la fin du XXème siècle, Bruxelles, Bruylant, 1997, pp. 7-31 (em inglês: "Globalization of World Society. How to Conceive of Modern Society?", International Review of Sociology, 1997, 7, 1).

- (2000a), Organisation und Entscheidung (Organização e Decisão), Opladen, Westdeutscher Verlag.

- (2000b), Die Politik der Gesellschaft (A política da sociedade), Francoforte, Suhrkamp.

Merton, Robert K. (1948), "Discussion" American
Sociological Review, 13, pp. 164-168 (Comentário ao texto de Talcott Parsons, "The Position of Sociological Theory", American Sociological Review, 13, pp. 156-164).

- (1968), "On Sociological Theories of the Middle Range", in: Id., Social Theory and Social Structure, Glencoe, Free Press, pp. 39-72.

Neves, José Pinheiro (2005), A individuação técnica na actualidade, Tese de doutoramento defendida na Universidade do Minho em Abril de 2005.

SAntos, Boaventura de Sousa (2002), Towards a New Legal Common Sense, London/Edinburgh, Butterworths.

Touraine, Alain (2005), Un nouveau paradigme. Pour comprendre le monde d'aujourd'hui, Paris, Fayard.

Weber, Max, (1921), Wirtschaft und Gesellschaft, Tübingen, Mohr (Siebeck), 1921.

Wehner, Cecilie, Abrahamson, Peter, Murphy, Fiona, Clark, Robert, Hajighasemi, Ali Hort, Sven E. (2005), "The Role Of The Different Actors In The Development Of Social Policy", in Jorens, Yves (ed.), Social Protection in Europe. Convergence? Integration, Accession and Labour. Final Report presented to the EC-DG Research, Ghent University, Department of Social Law, pp. 135-170. 